\title{
O TRABALHO INFANTIL DOMÉSTICO E SUAS CONSEQUÊNCIAS
}

Daírles Vieira Mendes, Claudia Regina de Oliveira Cantanhede 


\section{O TRABALHO INFANTIL DOMÉSTICO E SUAS CONSEQUÊNCIAS}

\section{CHILD DOMESTIC WORK AND ITS CONSEQUENCES}

Daírles Vieira Mendes ${ }^{1}$, Claudia Regina de Oliveira Cantanhede ${ }^{2}$

\section{RESUMO}

A finalidade deste trabalho consiste em analisar a evolução da sociedade em relação ao respeito aos direitos da criança e do adolescente, fortalecendo uma maior percepção da exploração do trabalho infantil, que ainda persiste de forma absurda na sociedade brasileira. O trabalho infantil não é um problema específico do Brasil. Só que com diferenças de intensidade e de gravidade, sendo esse talvez um dos enigmas que o tornam tão difícil de erradicar. Milhares de crianças ainda deixam de ir à escola e de terem seus direitos preservados, e trabalham desde a mais tenra idade na lavoura, campo, fábrica ou casas de família, em regime de exploração ou quase de escravidão.

Palavras-chave: sociedade; trabalho infantil; proteção; exploração.

\section{ABSTRACT}

The purpose of this paper is to analyze the evolution of society in relation to respect the rights of children and adolescents, strengthening greater attention to the exploitation of child labor, which still persists ridiculously in Brazilian society. Child labor is not a problem specific in Brazil. But with differences of intensity and seriousness, this being perhaps one of the puzzles that make it so difficult to eradicate. Thousands of children still fail to go to school and have their rights protected, and work from an early age on the farm, field, factory or family houses in a system of exploitation or almost slavery.

Keywords: society; child labor, protection; exploitation.

\section{INTRODUÇÃO}

O presente trabalho foi elaborado usando como referência a pesquisa bibliográfica, com o intuito de demonstrar as diversas modalidades de

$1 \quad$ Bacharela em Direito pela Universidade Ceuma.

2 Mestre em Educação pela Universidade Federal do Rio Grande do Sul - UFRGS.

Professora da Universidade CEUMA. E-mail: c.r.back@bol.com.br 
trabalho infantil, e dar ênfase ao mais silencioso de todos, que é o trabalho infantil doméstico.

Há uma cultura de aceitação do trabalho infantil. Quem atua com essa temática, logo verifica isso. Se for discutir o tema com a sociedade, você ouve recorrentemente se falar que 'é melhor estar trabalhando do que na rua'.

A origem do trabalho infanto-juvenil está atrelada ao princípio do trabalho humano. Na Antiguidade, o trabalho da criança e do adolescente acontecia no âmbito doméstico, sendo voltado para o aprendizado de um ofício e de um sistema de produção familiar. O trabalho, como atividade laboral, ganhou proporções com a Revolução Industrial e a estruturação do regime econômico capitalista.

Neste sentido, diversas regulamentações jurídicas foram criadas ao longo da história para a proteção destes sujeitos, vítimas de opressão e exploração, visando assegurar-lhes um desenvolvimento integral e sadio.

Presume-se que há uma permissividade da sociedade em achar que esse tipo de trabalho é normal em razão dos inúmeros problemas sociais em nosso país. É óbvio que se a família não consegue gerar renda por si só, isso vai contribuir para trazer a criança e o adolescente para o trabalho.

Há uma distorção de valores, e às vezes se impõe à criança e ao adolescente o papel que seria do adulto, que é o de dar sustentação e condições de subsistência ao seio familiar.

Aponta-se, também, a insuficiência de políticas do poder público - ou mesmo ausência em alguns lugares - definidas para buscar a erradicação do trabalho infantil.

O trabalho infantil doméstico aparece em todos os indicadores de exploração da mão-de-obra de crianças e adolescentes. Apesar de presente nas estatísticas, os instrumentos para avaliar o problema ainda são raros. Há poucos estudos sobre o tema e mesmo o marco legal para o seu enfrentamento ainda não está plenamente definido.

\section{EXPLORAÇÃO DO TRABALHO INFANTIL NO MUNDO}

Trabalho infantil é todo esforço físico e mental desempenhado por pessoas que não possuem idade adequada, como crianças e adolescentes. Grande parte dos países possui leis trabalhistas que condenam o trabalho infantil. Essa prática é ilegal e reconhecida como crime.

O trabalho infantil integra a história da humanidade. Há referências, inclusive na Bíblia, à exploração de crianças escravas e a repulsa que isso causava já naquela época (Vivarta, 2008).

Os abusos, no entanto, persistem até hoje. A Organização 
nternacional do Trabalho (OIT) e o UNICEF estimam em 240 milhões o número de crianças de 5 a 14 anos que trabalham no mundo.

Mesmo sendo repudiado pela sociedade, o trabalho infantil acontece em diferentes partes do mundo. De acordo com o Fundo das Nações Unidas para a Infância - UNICEF, os principais causadores desse fenômeno são basicamente a pobreza e o desemprego.

Diante dessa realidade, muitas crianças e adolescentes que vivem nas cidades executam tarefas diárias de trabalho, como vender balas, engraxar sapatos, além de entregar panfletos.

No campo, os jovens desempenham tarefas mais pesadas como colher algodão, cortar cana-de-açúcar, quebrar pedras, trabalhar em carvoarias, entre muitas outras ocupações árduas.

De acordo com a Organização Internacional do Trabalho - OIT, os trabalhadores infantis vivem em países subdesenvolvidos e em desenvolvimento. Segundo a OIT, existem no mundo, aproximadamente, 250 milhões de crianças (idades entre 5 e 14 anos) realizando tarefas de trabalho. Desse total, pelo menos 120 milhões trabalham o dia todo, não frequentam a escola e nem brincam.

Do número total de crianças trabalhadoras no mundo, cerca de 200 milhões delas não usufruem de descanso semanal. Outro dado importante é a incidência de casos de trabalho infantil na zona rural dos países.

Pelo menos dois terços dos acidentes de trabalho que acontecem em alguns países são provenientes de trabalhadores infantis.

O trabalho infantil tornou-se um problema global, isso em virtude de sua ocorrência tanto em países pobres como em países ricos.

Apesar do avanço legislativo, subsistem problemas complexos que não foram ainda satisfatoriamente solucionados, como o abuso do trabalho infantil em colheitas, incompatível com a condição dos menores, expondoos à duração excessiva em sua atividade sob o sol.

\section{TRABALHO INFANTIL DOMÉSTICO E SUAS CONSEQUÊNCIAS}

O trabalho infantil doméstico caracteriza-se como aquele que é realizado por crianças e adolescentes, fora de suas casas e dentro da casa de terceiros, que tem sido executado em troca de um salário ínfimo ou de uma promessa de roupa, escola e alimentação.

Apesar de ser uma velha prática no Brasil, parte da nossa herança escravocrata, o trabalho infantil era até pouco tempo ignorado pela maioria das pesquisas. $O$ assunto só chegou à pauta, graças a pesquisas realizadas em seis estados brasileiros: Pará (pelo Centro de Defesa da Criança e do 
Adolescente - Emaús), Minas Gerais (pelo ICA da PUC-MG), Pernambuco (pelo Centro Dom Hélder Câmara de Estudos e Ação Social), Bahia (pelo Ceafro), Maranhão (pelo Terre des hommes) e Mato Grosso do Sul (pelo Ministério do Trabalho).

As organizações não-governamentais receberam apoio da OIT, do Unicef e da Save the Children/Reino Unido, entre outras instituições, para a realização de um amplo levantamento sobre o problema, imprescindível para uma maior compreensão dessa realidade brasileira.

O trabalho doméstico é uma das formas de exploração de mão-deobra infantil mais difundidas e menos pesquisadas. No mundo todo, milhões de crianças trabalham na obscuridade de casas fechadas, principalmente como empregadas domésticas.

Uma análise de pesquisas realizadas pelo Governo Federal, organismos nacionais e internacionais, universidades e organizações nãogovernamentais mostra que as mulheres respondem por $95,6 \%$ do trabalho doméstico, sendo que $43,7 \%$ delas são meninas entre 12 e 15 anos.

Um terço começou a trabalhar entre os 5 e os 11 anos. Segundo Neide Castanha, em seu estudo para a OIT:

"A ideia do trabalho doméstico para meninas é muito forte em nossa sociedade, quase que fazendo parte da vida das crianças de famílias pobres, que dimensionam os serviços do lar como parte da formação infantil e sua passagem para lares de terceiros como uma possibilidade de aprendizado e melhoria de oportunidades para ascensão social".

Em 2002, graças a estudos feitos por entidades da sociedade civil e pela Organização Internacional do Trabalho, o trabalho infantil deixou de ser invisível. Tirá-lo do anonimato foi um avanço mas, a exemplo do que acontece com a cobertura do trabalho infantil em geral, ainda é necessário ampliar o foco das matérias, discutindo causas, consequências e possíveis soluções.

Segundo o SINDOMÉSTICO, as funções e ações desempenhadas por crianças e adolescentes em casas de terceiros, caracterizadas como trabalho infantil doméstico são: cozinhar, lavar roupa, cuidar de crianças, passar roupas e limpar casa, entre outros.

Existem diversos fatores que contribuíram para o surgimento da prática da exploração do trabalho infantil doméstico, sejam as condições socioeconômicas dessas crianças e adolescentes ou as crenças e valores instituídos culturalmente em nossa sociedade.

A inexistência de alternativas que possibilitem acesso a melhores condições de vida para os filhos - o que inclui o acesso à educação, saúde, 
vestuário, alimentação - impulsiona as famílias a entregarem seus filhos a terceiros para trabalharem, numa perspectiva de evitar que passem "necessidades".

Ao nos depararmos com o fenômeno do trabalho infantil doméstico, constatamos que esse universo é constituído, em sua grande maioria, por meninas, na faixa etária de 05 a 15 anos (DIEESE, 2006).

Segundo as pesquisas da OIT realizadas em Minas Gerais, Pernambuco e Pará, $64,2 \%$ das pequenas trabalhadoras ganham menos de meio salário mínimo. A jornada acima de 40 horas semanais é o cotidiano de $52,8 \%$ delas. A maioria não tira férias $(55,5 \%)$ e desconhece os seus direitos trabalhistas $(60,6 \%)$. Outra parcela não tem sequer remuneração trabalha em troca de casa e comida.

Enquanto, em geral, o trabalho infantil atinge mais meninos do que meninas, quando se trata de trabalho doméstico, a situação se inverte e fica mais aguda: $94 \%$ das crianças e adolescentes trabalhando em casas de família são meninas, segundo a Pesquisa Nacional por Amostra de Domicílios (PNAD, 2008).

A OIT cita ainda como os riscos mais comuns presentes na vida dessas crianças a submissão a jornadas longas e muito pesadas de trabalho, salários baixos ou inexistentes e uma grande vulnerabilidade ao abuso físico, emocional ou sexual.

Segundo Renato Mendes": "Muitas trabalhadoras domésticas que vêm de uma situação de trabalho infantil têm um perfil mais submisso e introvertido, características desenvolvidas por uma criança ou adolescente que assume um papel de adulto dentro de casa".

Portanto, uma menina que presta serviço doméstico dificilmente encontra oportunidades educativas e de desenvolvimento pessoal, conforme reitera o autor.

Luiz Henrique Ramos Lopes ${ }^{4}$ admite que o trabalho infantil doméstico é especialmente difícil de se de fiscalizar: "Por causa da inviolabilidade domiciliar, não existe uma ação fiscal contra o trabalho doméstico como há em outras áreas. Não se pode entrar na casa de alguém sem um mandado judicial".

3 Coordenador Nacional do Programa para Erradicação do Trabalho da Organização Internacional do Trabalho (OIT).

4 Coordenador da divisão de trabalho infantil do Ministério do Trabalho e Emprego (MTE). 


\section{Características e riscos do trabalho infantil doméstico}

O trabalho infantil doméstico viola os direitos humanos de crianças e adolescentes à vida, à saúde, à educação, a brincar, ao lazer, e ainda acarreta prejuízos que comprometem o seu pleno desenvolvimento físico, psicológico, cognitivo e moral, definido como uma das piores formas de trabalho infantil no Decreto $n^{\circ} 6.481 / 2008$ :

Art. $1^{\circ}$ Fica aprovada a Lista das Piores Formas de Trabalho Infantil (Lista TIP), na forma do Anexo, de acordo com o disposto nos artigos 3, "d", e 4ำ da Convenção 182 da Organização Internacional do Trabalho - OIT, aprovada pelo Decreto Legislativo № 178, de 14 de dezembro de 1999 e promulgada pelo Decreto no 3.597 , de 12 de setembro de 2000 .

Atividade:

Serviço Doméstico

Descrição dos Trabalhos: Domésticos

Prováveis Riscos Ocupacionais: Esforços físicos intensos; isolamento; abuso físico, psicológico e sexual; longas jornadas de trabalho; trabalho noturno; calor; exposição ao fogo, posições antiergonômicas e movimentos repetitivos; tracionamento da coluna vertebral; sobrecarga muscular e queda de nível.

Prováveis Repercussões à Saúde: Afecções músculoesqueléticas (bursites, tendinites, dorsalgias, sinovites, tenossinovites); contusões; fraturas; ferimentos; queimaduras; ansiedade; alterações na vida familiar; transtornos do ciclo vigília-sono; DORT/ LER; deformidades da coluna vertebral (lombalgias, lombociatalgias, escolioses, cifoses, lordoses); síndrome do esgotamento profissional e neurose profissional; traumatismos; tonturas e fobias. ${ }^{5}$

O trabalho perigoso realizado por crianças é definido como qualquer atividade ou ocupação que, pela sua natureza ou tipo, tenha ou conduza a efeitos nocivos na segurança, saúde, desenvolvimento ou moral da criança.

Em termos gerais, o "trabalho perigoso" pode incluir o trabalho noturno e com horários prolongados, a exposição a maus-tratos ou abusos físicos, psicológicos ou sexuais, o trabalho subterrâneo, subaquático, em 5 htt://www.planalto.gov.br/ccivil_03/_ato2007-2010/2008/decreto/d6481.htm 
alturas perigosas ou em espaços confinados, o trabalho com maquinaria, equipamento ou ferramentas perigosas, ou que envolva o manuseio ou transporte de cargas pesadas e o trabalho em ambientes insalubres que possa, por exemplo, expor as crianças a substâncias, agentes ou processos perigosos, ou a temperaturas, níveis de ruído ou vibrações nocivas para a sua saúde.

Portanto, o "trabalho perigoso" executado por crianças é normalmente considerado como equivalente às piores formas de trabalho infantil, principalmente pelos danos potenciais e efetivos, bem como pela dificuldade de obtenção de dados nacionais confiáveis sobre as piores formas de trabalho, com exceção do trabalho perigoso, como a exploração sexual comercial e o envolvimento das crianças em conflitos armados.

\section{Números do trabalho infantil doméstico no Brasil}

A situação do trabalho infantil doméstico no Brasil pouco se alterou entre 2008 e 2011, de acordo com relatório divulgado pelo Fórum Nacional de Prevenção e Erradicação do Trabalho Infantil (FNPETI, 2013).

O quantitativo de crianças e adolescentes na faixa etária entre 5 e 17 anos que trabalhavam caiu $17,9 \%$ nesse período e também o número de casos de crianças e adolescentes ocupados no trabalho infantil doméstico diminuiu de 325 mil (2008) para 258 mil (2011) - uma redução de 67 mil casos.

Em termos proporcionais, a redução foi de apenas 0,2 ponto percentual: de 7,2\% em 2008 para $7 \%$ em $2011^{6}$.

Esse número pode ser ainda maior. Em 2011, dos 3,7 milhões de crianças e adolescentes em situação de trabalho infantil, $57,5 \%$, ou seja, 2,1 milhões de crianças e adolescentes trabalhavam e ainda eram responsáveis pelas tarefas domésticas em suas próprias casas.

Ou seja, as mesmas atividades (lavar, passar, cozinhar, limpar a casa, cuidar de crianças, etc.) realizadas por aqueles que prestam serviços domésticos para outras famílias, são realizadas também por eles em suas próprias casas ${ }^{6}$.

Em 2011, do universo de 258 mil crianças e adolescentes (entre 5 e 17 anos) em situação de trabalho infantil doméstico que prestavam serviços para outras famílias, 102.668 (39,8\%) estavam na Região Nordeste; 66.663 pessoas $(25,9 \%)$ no Sudeste; 35.590 (13,8\%) no Norte; 34.755 (13,5\%) no Sul; e 18.015 (7\%), no Centro-Oeste.

No mesmo período, os Estados de Minas Gerais (31.316), Bahia (26.564), São Paulo (20.381) e Pará (19.309) apresentavam os maiores 6 http://www.unicef.org/brazil/pt/media_25610.htm 
números absolutos de crianças e adolescentes em situação de trabalho doméstico.

Apesar da redução do número de ocupados nos serviços domésticos no período de 2008 a 2011, de 325 mil para 258 mil, os Estados do Pará, Alagoas, Maranhão, Piauí, Rio Grande do Norte, Espírito Santo e Rio de Janeiro apresentaram aumento proporcional de crianças e adolescentes ocupados em atividades domésticas.

Em 2011, 30 mil crianças e adolescentes em situação de trabalho infantil - ou seja, $11,56 \%$ dos 258 mil - viviam nas regiões metropolitanas de Salvador, Fortaleza, Distrito Federal, Belo Horizonte, Belém, Curitiba, Recife, Rio de Janeiro, Porto Alegre e São Paulo.

Segundo Isa Oliveira ${ }^{7}$, as estatísticas mostram o lento avanço das políticas públicas no enfrentamento ao trabalho infantil doméstico. "É importante que o tema seja priorizado pelas políticas públicas e que ações intersetoriais sejam adotadas e implementadas".

\section{Consequências do trabalho infantil doméstico}

Pode-se destacar como a primeira consequência e talvez a mais importante, a diminuição no rendimento escolar: "os que se iniciaram como empregados domésticos possuíam em média 1,6 anos de estudos a menos do que aqueles que começaram a trabalhar em outras ocupações" (OIT, 2003, p.2).

Dessa forma, a baixa escolaridade na estrutura familiar perpetuase por interferência do trabalho infantil. Segundo dados do IBGE, cerca de $30 \%$ das crianças exploradas nesta modalidade de trabalho são de família cujos pais não possuem nenhum ano de escolaridade (IBGE/1999) ${ }^{8}$.

Aos problemas sociais que o trabalho infantil doméstico causa se somam os prejuízos causados à saúde das crianças e adolescentes.

Queimaduras, intoxicações por produtos químicos, cortes com facas, dores musculares, desvios na coluna ocasionados por esforço físico com objetos pesados e ferimentos causados por animais domésticos são danos comuns sofridos pelas crianças e adolescentes domésticas. ${ }^{9}$

Porém, o prejuízo maior ocorre no desenvolvimento psicológico dessas crianças. Sabendo-se que a criança é submetida ao mesmo regime de trabalho imposto ao adulto, verifica-se que há brusca ruptura para a maturidade, responsabilidade e força, tomando-se adultas precocemente,

\footnotetext{
$7 \quad$ Isa de Oliveira, secretária executiva do FNPETI.

8 http://jus.com.br/artigos/30711/apontamentos-sobre-o-trabalho-infantil-domestico/2\#ixzz3bjK9kYV3

$9 \quad$ Idem, ibdem
} 
queimando etapas da infância, fundamentais para o desenvolvimento sadio e harmonioso do ser humano ${ }^{10}$.

\section{CONCLUSÃO}

O trabalho infantil doméstico é de difícil constatação, pois dentre todas as modalidades de trabalho infantil, dissemina-se entre quatro paredes, no silêncio dos lares brasileiros.

Verificou-se na pesquisa que a causa determinante para o nascedouro da exploração do trabalho está indiscutivelmente relacionado à pobreza. As famílias incentivam seus filhos a trabalharem desde tenra idade para aumentar a renda familiar e garantir o sustento do lar. Em outros casos, as famílias, em razão da vulnerabilidade econômica, permitem que suas crianças e adolescentes trabalhem para empregadores, sendo que estes, por sua vez, pagam a título de salário, valores írrisórios.

Nesta fase da vida, o trabalho é altamente prejudicial ao desenvolvimento físico, psicológico, educacional, moral, social, sendo que alguns tipos de trabalhos causam malefícios à saúde.

Por comprometer o futuro desses indivíduos, é necessário que o Governo Federal promova cada vez mais ações, planos e programas, visando coibir a utilização do labor de crianças e adolescentes.

Porém, existe a concepção bastante presente de que o trabalho dignifica o ser humano, molda o caráter, portanto, é benéfico a crianças e adolescentes.

Percebemos que, quando se fala de defesa do trabalho infantil, fala-se com certo preconceito de classe, uma discriminação em relação à população mais pobre.

Num momento em que filhos e filhas das classes altas adiam cada vez mais a entrada no mercado de trabalho, preferindo antes concluir cursos de graduação, pós-graduação e temporadas de estudos no exterior para conseguir postos mais bem pagos, os filhos e filhas das classes baixas ingressem no mercado cada vez mais cedo para auxiliar na manutenção financeira familiar.

Para erradicar a exploração do trabalho de crianças e adolescentes é necessária a atuação governamental em conjunto com os órgãos institucionais comprometidos em defender os direitos previstos na legislação brasileira, seja por meio de políticas públicas ou por implementação de ações, estratégias e programas com a finalidade de afastar as crianças e adolescentes do trabalho e fazer com que frequentem a escola. Somente através do conhecimento adquirido, crianças e adolescentes terão mais $10 \quad$ Idem, ibdem 
chances de sair da pobreza, obter igualdade de condições na procura de melhores empregos e, consequentemente, melhor qualidade de vida.

Assim, constitui dever da família, da comunidade, da sociedade em geral e do Poder Público zelar e assegurar os direitos das crianças e adolescentes.

\section{REFERÊNCIAS}

ACIOLY FILHO, Antônio Carlos. Lineamentos históricos acerca do trabalho infantil no Brasil e no mundo. Disponível em: <http://www.viajus.com.br/ viajus.php?pagina=artigos\&id=597\#>. Acesso em: 23 mai 2015.

AMIN, Andréa Rodrigues. Curso de direito da criança e do adolescente: aspectos teóricos e práticos. Coordenadora Kátia Regina Ferreira Lobo Andrade Maciel. IBDFAM/ LUMEN JURIS: Rio de Janeiro, 2006.

A Situação do trabalho no Brasil na primeira década dos anos 2000 / Departamento Intersindical de Estatística e Estudos Socioeconômicos. São Paulo: DIEESE, 2012.

Boas Práticas: Integração de gênero nas ações contra o trabalho infantil - Organização Internacional do Trabalho - Programa Internacional para a Eliminação do Trabalho Infantil (IPEC) - Genebra, 2004.

BRASIL. Constituição Federal (1988). 9. ed. São Paulo: Vade Mecum, Saraiva, 2010.

. ECA (1990). Estatuto da Criança e do Adolescente. 9. ed. São Paulo: Vade Mecum, Saraiva, 2010.

. Plano Nacional de Prevenção e Erradicação do Trabalho Infantil e Proteção do Adolescente Trabalhador. 2 ed. - Brasília: Ministério do Trabalho e Emprego, 2011.

dos microdados da PNAD (2008 - 2011). FNPETI, 2013.

O Trabalho Infantil Doméstico no Brasil. Avaliação a partir O Brasil e o Trabalho Infantil no início do séc. 21. Brasília: OIT, 2004.

Crianças Invisíveis: o enfoque da imprensa sobre o trabalho infantil e outras formas de exploração. Coord. Veet Vivarta. São Paulo: Cortez , 2003.

LIMA, Danilo Chaves. Trabalho infantil doméstico. Revista Jus Navigandi, Teresina, ano 20, n. 4208, 8 jan. 2015. Disponível em: <http:/jus.com.br/ artigos/30711>. Acesso em: 27 maio 2015. 
Mapa de Indicativos do Trabalho da Criança e do Adolescente. 3. ed. Brasília: TEM, SIT, 2005.

Oficina Sistema de Garantia de Direitos e a Erradicação do Trabalho Infantil. Fundação das Nações Unidas para a Infância - UNICEF, Brasília, 2004.

Trabalho Infantil Doméstico: Não deixe entrar na sua casa. Fórum Estadual de Erradicação do Trabalho Infantil do Maranhão - FEPETIMA, São Luís, 2009. 